\title{
ESTUDO DE CASO DOS IMPACTOS DA CRISE GLOBAL NOS CRITÉRIOS COMPETITIVOS ESTRATÉGICOS DE EMPRESAS
}

\section{CASE STUDY OF IMPACTS OF THE CRISIS IN GLOBAL STRATEGIC BUSINESS COMPETITIVE CRITERIA}

\author{
Beatriz Lúcia Salvador Bizotto ${ }^{1}$; Carlos Alberto Costa $^{2}$; Charles Rui ${ }^{3}$; \\ Evandro Lazzarotto ${ }^{4}$; Ricardo Antonio Reche ${ }^{5}$; Maria Emília Camargo ${ }^{6}$ \\ ${ }^{1}$ Universidade Caxias do Sul - UCS- Caxias do Sul - Brasil \\ beatriz.bizotto@uol.com.br \\ ${ }^{2}$ Universidade Caxias do Sul - UCS- Caxias do Sul - Brasil \\ cacosta@ucs.br \\ ${ }^{3}$ Universidade Caxias do Sul - UCS- Caxias do Sul - Brasil \\ crui@uol.com.br \\ ${ }^{4}$ Universidade Caxias do Sul - UCS- Caxias do Sul - Brasil \\ lazzarotto.e@ognibene.com \\ ${ }^{5}$ Universidade Caxias do Sul - UCS- Caxias do Sul - Brasil \\ ricardo.reche@yahoo.com.br \\ ${ }^{6}$ Universidade Caxias do Sul - UCS- Caxias do Sul - Brasil \\ kamargo@terra.com.br
}

\begin{abstract}
Resumo
No segundo semestre de 2008 iniciou a crise econômica que provocou a influência nos resultados organizacionais de diversas empresas. Os gestores tiveram que ser ágeis em análise, para decidir em quais critérios competitivos as empresas estavam ameaçadas e definir estratégias para estas permanecerem no mercado globalizado. $O$ objetivo desta pesquisa foi diagnosticar quais foram as ações adotadas por duas empresas no período de crise, sob a ótica dos critérios competitivos, repensando suas estratégias de operação. A metodologia utilizada foi classificada como pesquisa exploratória (estudo de caso), através de entrevistas com questões semi-estruturadas. Para esta pesquisa utilizou-se os cinco critérios competitivos abordados por Paiva et al (2004). Como objetos desta pesquisa foram selecionadas duas empresas exportadoras: uma do segmento de alimentos e outra de autopeças. Os resultados mostraram que, apesar das diferenças de natureza e atuação destas empresas, as mesmas apresentaram ações com grau de significância comum e, por já terem estratégias definidas antes do período da crise, foram afetadas superficialmente.
\end{abstract}

Palavras-chave: crise global; critérios competitivos; categorias de decisão; estratégias de operação.

\section{Introdução}

Na visão de Ching (1999) a economia mundial está sofrendo transformações com a globalização. Reflexos estão sendo sentidos nos segmentos industriais em relação ao aumento da competitividade, ao acesso a novas tecnologias e a mudança comportamental do mercado 
consumidor.

$\mathrm{Na}$ visão de Vasconcelos et al (2005), o mundo tornou-se globalizado e o fato de que qualquer crise no mundo vai afetar as empresas, faz com que estas devam ser muito mais rápidas no estabelecimento de ações em termos de previsão e oportunidades. Além disso, o crescente número de alianças entre organizações tem proporcionado a formação de verdadeiras redes, configurando o que se chama hoje de Sociedade em Rede.

\begin{abstract}
A essência da formulação estratégica é lidar com a competição. Entretanto, tende-se a perceber a competição de forma muito limitada e pessimista. Os clientes, os fornecedores, os novos entrantes em potencial e os produtos substitutos são todos competidores, que podem ser mais ou menos proeminentes ou ativos, dependendo do setor industrial (PORTER; MONTGOMERY, p. 11, 2001).
\end{abstract}

Porter (2003) destaca que uma das questões centrais em estratégia competitiva é a posição relativa de uma empresa dentro de seu segmento, e a base fundamental para obter um desempenho acima da média é a criação de uma vantagem competitiva sustentável. Existem dois tipos básicos de vantagem competitiva: liderança em custo e diferenciação. Conforme Paiva et al. (2004), destas duas vantagens competitivas surgem cinco critérios competitivos na área de operações que se relacionam à estratégia de negócio: custo, diferenciação, entrega, a flexibilidade e inovatividade.

Paiva et al. (2004), também sugere que as empresas enfatizem a combinação de alguns desses critérios prioritariamente, pois a tentativa em atender todas as dimensões simultaneamente pode ser arriscada. A especificação e esclarecimento de quais critérios são prioritários na empresa, orientarão a função de produção na definição de seu papel na estratégia competitiva.

Este trabalho analisa o impacto da crise econômica e quais as ações que as empresas exportadoras adotaram para minimizar os seus efeitos sobre suas operações. O estudo foi desenvolvido sob a ótica dos cinco critérios competitivos abordados pela literatura, i.e. custos, diferenciação, entrega, inovação e flexibilidade. A pesquisa foi conduzida de forma exploratória (estudo de caso), do tipo qualitativa, por meio de um roteiro de entrevista semi-estruturado.

Desta forma, a seção seguinte apresenta uma revisão sobre o tema estratégia competitiva no cenário global. A seção 3 apresenta a metodologia empregada, seguida pelo estudo de caso das empresas e, finalmente, as considerações finais.

\title{
2. Estratégias empresariais
}

Para Porter e Montgomery (2001), estratégia é a busca deliberada de um plano de ação para desenvolver e ajustar a vantagem competitiva de uma empresa. Além disso, afirmam que para uma indústria, o competidor mais perigoso é aquele que tem o comportamento semelhante. Assim, a vantagem para a empresa em relação aos competidores reside nas diferenças de estratégias. Entretanto, tende-se a perceber a competição de forma muito limitada e pessimista. 
Qualquer que seja seu esforço coletivo, o objetivo estratégico da empresa é encontrar uma posição no setor onde possa melhor se defender contra essas forças ou influenciá-las a seu favor. As forças competitivas determinam a lucratividade de um setor e, portanto, são importantes na formulação estratégica (PORTER; MONTGOMERY, p. 12, 2001).

Existem dois tipos básicos de vantagem competitiva: liderança em custo e diferenciação, que resultam da habilidade de uma empresa em lidar com as cinco forças competitivas (entrada de novos concorrentes, ameaça de substitutos, poder de negociação de compradores, poder de negociação dos fornecedores, rivalidade entre concorrentes existentes) de forma melhor do que seus rivais.

O quadro 1 demonstra a combinação dos dois tipos básicos de vantagem competitiva com o escopo das atividades de uma empresa, levando a três estratégias genéricas (PORTER, 2003).

Quadro 1 - Estratégias genéricas segundo Porter

\begin{tabular}{|l|l|l|}
\hline \multicolumn{1}{|c|}{ CUSTO } & \multicolumn{1}{|c|}{ DIFERENCIAÇÃO } & \multicolumn{1}{c|}{ ENFOQUE } \\
\hline & $\begin{array}{l}\text { É a estratégia onde a empresa } \\
\text { busca ser a única em sua indústria, } \\
\text { em dimensões valorizadas pelos } \\
\text { É a estratégia onde a empresa } \\
\text { parte para tornar-se o produtor de } \\
\text { baixo custo em sua indústria. }\end{array}$ & $\begin{array}{l}\text { Torna-se uma estratégia viável quando há } \\
\text { a em competir em um ambiente } \\
\text { estres dentro de uma indústria. Uma } \\
\text { recompensada através do preço, ou atua com estratégia no } \\
\text { enfoque, seleciona um segmento ou um } \\
\text { grupo de segmentos na indústria e adapta } \\
\text { sua estratégia para atendê-los, excluindo } \\
\text { outros segmentos. }\end{array}$ \\
\hline
\end{tabular}

Fonte: Adaptado Porter (2003)

O quadro 2 descreve as vantagens estratégicas como um pré-requisito do sucesso, conforme Slack (1993):

Quadro 2 - Vantagens Estratégicas

\begin{tabular}{|c|c|c|c|}
\hline QUALIDADE & VELOCIDADE & ENTREGA & FLEXIBILIDADE \\
\hline $\begin{array}{l}\text { Mais do que qualquer } \\
\text { outro objetivo de } \\
\text { desempenho, tem uma } \\
\text { vantagem que dá grande } \\
\text { poder motivacional. } \\
\text { Qualidade é algo pelo que } \\
\text { nós sentimos valer a pena } \\
\text { lutar. Qualidade é "fazer o } \\
\text { que deveríamos estar } \\
\text { fazendo," é "não cometer } \\
\text { erros," é ser "livre de } \\
\text { erros." }\end{array}$ & $\begin{array}{l}\text { O cliente externo vê a } \\
\text { velocidade de uma } \\
\text { operação como o período } \\
\text { total que ele tem de esperar } \\
\text { entre solicitar o produto e } \\
\text { recebê-lo. }\end{array}$ & $\begin{array}{l}\text { A relação entre tempo de } \\
\text { fluxo e confiabilidade } \\
\text { também se aplica da } \\
\text { mesma forma para dentro } \\
\text { da operação. }\end{array}$ & $\begin{array}{l}\text { Tornou-se uma das } \\
\text { virtudes da manufatura } \\
\text { mais em moda. Mercados } \\
\text { turbulentos, concorrentes } \\
\text { ágeis e rápidos } \\
\text { desenvolvimentos em } \\
\text { tecnologias forçaram a } \\
\text { administração da } \\
\text { manufatura a reavaliar sua } \\
\text { habilidade de modificar o } \\
\text { que faz e como faz. Isto é } \\
\text { flexibilidade - habilidade } \\
\text { de mudar, de fazer algo } \\
\text { diferente. }\end{array}$ \\
\hline
\end{tabular}

Fonte: Adaptado Slack (1993)

\subsection{Critérios competitivos e categorias de decisão}

Segundo Paiva et al. (2004) existem cinco critérios competitivos na área de operações que se relacionam à estratégia de negócio: 
a) Custo: neste critério as empresas decidem por produzir grandes volumes com margens reduzidas;

b) Diferenciação através da qualidade: neste caso a competitividade é obtida através de um desempenho superior dos produtos em relação aos concorrentes;

c) Entrega: neste critério a empresa compete com base em sua estrutura e capacidade de mobilizar recursos para atender as demandas do cliente de forma ágil, com curto prazo de entrega;

d) Flexibilidade: a empresa sustenta sua vantagem competitiva através da capacidade de absorver rapidamente as mudanças em lotes de produção não-padronizados, bem como mudanças no tipo de produto a produzir;

e) Inovatividade: a habilidade da empresa em lançar novos produtos e/ou serviços em um curto espaço de tempo.

De acordo com Hayes e Ninemeier (2005), as categorias de decisão para a estratégia de produção são as seguintes: capacidade, integração vertical e relação com fornecedores, instalações, informação e processos tecnológicos, alocação de recursos e sistemas de orçamento/capital, recursos humanos, sistemas de controle e planejamento do trabalho, sistemas da qualidade, sistemas de indicadores, sistemas de desenvolvimento de produto, processos e organização.

\subsection{Estratégias globais}

O desequilíbrio imposto pela globalização possibilita uma maior cooperação entre as organizações que interagem associativamente com outros agentes econômicos. Novamente exige-se uma adaptação organizacional, através da eliminação de novas barreiras organizacionais, agora impostas pelo ambiente externo.

Assim, no processo de criação de vantagens competitivas, é necessário alinhar a estratégia competitiva e a competência essencial. Em suma, uma empresa, para ser competitiva, precisa realmente compreender como se articulam competência essencial e estratégia empresarial.

Segundo Bonaglia e Goldstein (2006), a globalização é um fenômeno multidimensional e suas atividades fundamentais atingem um grau de integração elevado do ponto de vista temporal e geográfico. Ao mesmo tempo em que pode produzir efeitos negativos e criar novos desafios, também traz novas oportunidades.

Para Málaga (2007), quando duas ou mais empresas se combinam para formar uma nova empresa, deixam de existir legalmente e seus respectivos acionistas se tornam acionistas desta nova entidade. $\mathrm{O}$ crescente número de alianças entre organizações tem proporcionado a formação de verdadeiras redes, configurando o que se chama hoje de Sociedade em Rede. Observa-se que a maior parte dos produtos das empresas são produzidos nestas redes, e não mais isoladamente por 
uma única empresa, conforme Vasconcelos et al. (2005).

A habilidade de compartilhar atividades na cadeia de valor, segundo Porter e Montgomery (2001), é a base para a competitividade empresarial. Nesse sentido, a produtividade, a qualidade e a redução de custos, embora não devam ser ignoradas pelos gestores, não são mais geradores de vantagem competitiva, pois se tornam o mínimo requerido para a sobrevivência da empresa.

\begin{abstract}
A cadeia de fornecimento também faz parte da cadeia de valor, pois é de fundamental importância para a competitividade empresarial. As empresas já não competem apenas como autônomas, mas sim como cadeias de abastecimento. Ao invés de marcas contra marcas de fábrica ou loja versus loja, agora é fornecedores de marca-loja contra fornecedores de marca-loja, ou a cadeia de abastecimento versus a cadeia de abastecimento. Neste ambiente competitivo, o sucesso do único negócio dependerá da capacidade de integrar a gestão da empresa na rede de relações empresariais (COOPER; LAMBERT, 2000).
\end{abstract}

No que se refere à evolução na qualidade e produtividade, destaca-se, segundo Chase et al. (2006), o Sistema Toyota da Produção. O mesmo está baseado em duas filosofias centrais à cultura japonesa: a eliminação das perdas e o respeito pelas pessoas. Os sete elementos que abordam a eliminação das perdas são: as redes focadas da fábrica, a tecnologia em grupo, a qualidade na fonte, a produção JIT - Just-in-time, a programação uniforme da fabrica, o sistema Kanban de controle da produção e os tempos minimizados de preparação (setup).

Neste mundo globalizado, onde as forças competitivas impulsionam alianças entre empresas e fornecedores e reestruturações de redes produtivas, Carvalho et al. (2007) afirmam que as empresas estão sempre à busca de resposta rápida às aspirações do cliente e da eficiência interna. Um caminho a seguir é a associação entre empresas, por meio de parceria, com o objetivo de aumento da produtividade e, por conseguinte, competitividade.

As corporações, ao buscarem novas organizações no mercado, fazendo aquisições, com o objetivo de ampliar ou modificar seus portfólios de negócio, buscam obter vantagens competitivas, visto que é incomum nessa estratégia que uma corporação desenvolva novos produtos internamente, uma vez que evidências sugerem que a aquisição é uma maneira mais rápida, fácil de se modificar ou ampliar os portfólios de negócios (OLIVEIRA et al., p. 93, 2007).

A KPMG (2009, p. 8), conforme figura 1, realizou pesquisas nos últimos 14 anos e constatou que o número de fusões cresceu substancialmente no Brasil, sendo que no primeiro trimestre de 2009 ocorreram 101 operações deste nível. Estas informações foram classificadas pela KPMG de acordo com a origem do capital das transações, incluindo apenas empresas de capital nacional. As operações envolvendo adquirentes e adquiridas de capital nacional foram classificadas como domésticas, e as que envolveram empresas de origem distintas foram classificadas de mistas. 
Figura 1 - Evolução anual do número de transações

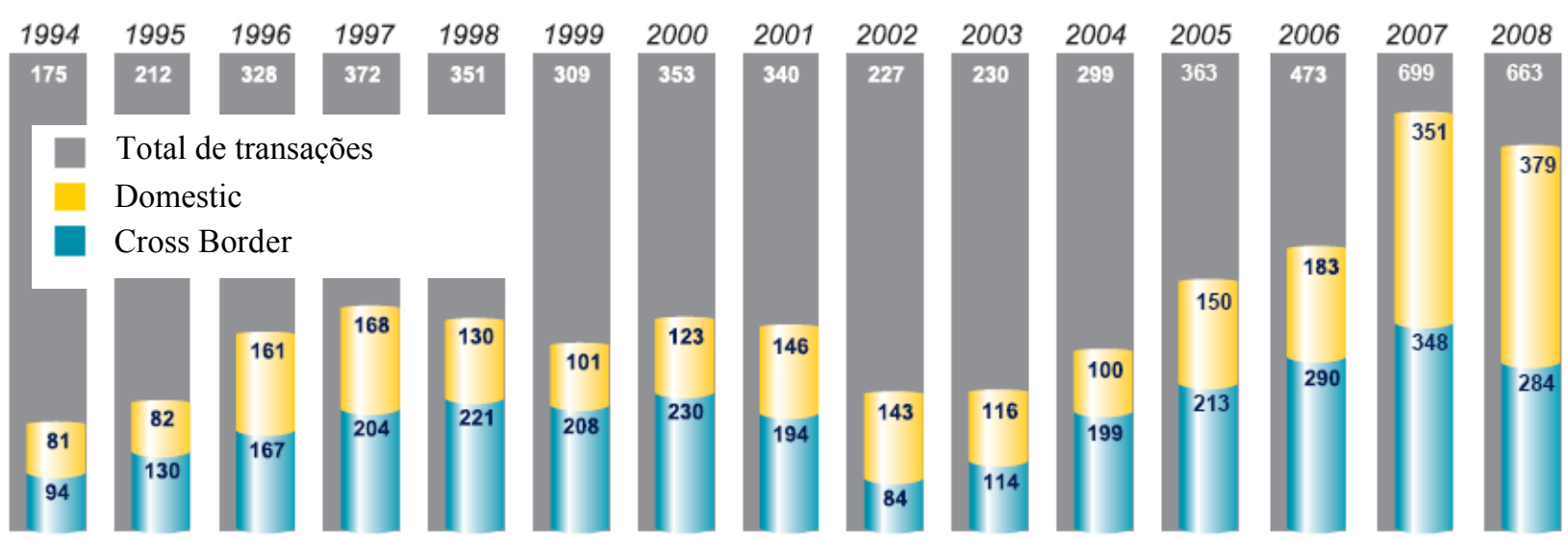

Fonte: KPMG, p. 8, 2009

\section{Aspectos metodológicos}

Este trabalho pode ser classificado como uma pesquisa exploratória (estudo de caso), do tipo qualitativa, realizada por meio de um roteiro de entrevista semi-estruturado. Segundo Yin (2008), o estudo de caso é uma investigação empírica que investiga um fenômeno contemporâneo em seu contexto real, especialmente quando os limites entre o fenômeno e o contexto não estão claramente definidos. Já para Gil (2002), a pesquisa exploratória tem por objetivo proporcionar maior familiaridade com o problema, com vistas a torná-lo mais explícito ou a construir hipóteses.

A elaboração do questionário baseou-se nos critérios competitivos apresentados por Paiva et al. (2004), i.e. custo, diferenciação, entrega, flexibilidade e inovação, na forma de questões associadas aos problemas percebidos e estratégias adotadas pelas empresas para minimizar os impactos de influência da crise econômica. Tais questões foram direcionadas sob três macrodimensões: os critérios competitivos, os clientes e o mercado. Especificamente para as questões associadas aos cinco critérios competitivos, foi solicitado aos entrevistados que atribuíssem, segundo o seu entendimento, o grau de importância de cada um deles para a sua empresa. Foi utilizada a escala Likert com pontuação (1) não é importante, (2) pouco importante, (3) necessário, (4) importante e (5) muito importante.

As entrevistas foram realizadas com os diretores e gerentes das empresas estudadas. Duas empresas exportadoras, sendo uma do segmento alimentício designado como "AL" e uma do segmento de autopeças, designada como "ME" foram analisadas. No caso da empresa ME foram entrevistados dois diretores e um gerente. $\mathrm{Na}$ empresa $\mathrm{AL}$ foram entrevistados um diretor e dois gerentes.

As entrevistas foram gravadas e transcritas para análise comparativa entre as respostas dos gestores de cada empresa e entre as empresas. As respostas foram analisadas textualmente, identificando-se os pontos de convergência e divergência. 
Por se tratarem de empresas com segmentos diferentes de atuação foi realizado teste estatístico para identificar o grau de significância entre as respostas das empresas, de acordo com os critérios competitivos e as categorias de decisão. Foi utilizado o teste não paramétrico de amostras independentes denominado Mann-Whitney, com nível de significância de 5\%.

Segundo Martins (2002, p. 268), este teste é usado para testar se duas amostras independentes foram retiradas de populações com médias iguais. Trata-se de uma interessante alternativa ao teste paramétrico para igualdade de médias (teste $\mathrm{t}$ ), pois o teste não exige nenhuma hipótese sobre distribuições populacionais e suas variâncias. Para Fávero et al. (2009), o teste de Mann-Whitney é um dos mais utilizados para duas amostras independentes, sendo uma alternativa ao teste paramétrico $t$, quando a amostra for pequena.

\section{A influência da crise nas estratégias das empresas}

\subsection{Caracterização das empresas}

Neste trabalho foram utilizadas duas empresas de segmentos distintos, conforme abordado no item 3.

A empresa ME é brasileira, com mais de 20 anos, de médio porte, que atua no segmento de autopeças em todo o mercado nacional e exporta para os cinco continentes. Tem 250 funcionários, possui faturamento anual de 65 milhões de reais e 40\% de exportação em 2008, sendo a segunda no seu segmento no mercado nacional. É uma empresa que, na visão de seus gestores, compete por custos e que trabalha com ênfase em inovação e entrega. Possui uma política de planejamento estratégico formalizado, com revisão anual. No caso desta empresa, havia um planejamento de processos de fusão e alianças, que foram repensados em função do cenário internacional.

A empresa AL, é uma empresa brasileira, com mais de 30 anos, familiar e de grande porte, que atua no segmento alimentício com ênfase no mercado gaúcho e exporta para os mercados russo, oriente médio e asiático. Tem 500 funcionários e apresenta o faturamento anual em torno de 60 milhões de reais e 55\% de exportação no ano de 2008, sendo considerada uma empresa não expressiva em termos de posicionamento no mercado nacional. É uma empresa que, na visão de seus gestores compete por diferenciação e que trabalha com ênfase em qualidade e entrega. Não possui uma política de planejamento estratégico formalizado. Entretanto, devido à sua dinâmica de mercado, trabalha com perspectivas de curto prazo. No caso desta empresa, por uma decisão de estratégia de novas instalações físicas, a mesma interrompeu as atividades de exportação, minimizando os impactos da crise sobre este mercado. 
Dentro da visão das empresas, ambas foram afetadas pelo cenário econômico iniciado no segundo semestre de 2008, que exigiu o planejamento de ações para minimizar os impactos sobre os resultados das organizações.

\subsection{Critérios competitivos e categorias de decisão}

Com relação aos critérios competitivos, as empresas foram questionadas no sentido de que atribuíssem, segundo o seu entendimento, o grau de importância de cada um dos cinco critérios para a sua empresa. Foi utilizada uma escala Likert com pontuação (1) não é importante, (2) pouco importante, (3) necessário, (4) importante e (5) muito importante.

A tabela 1 apresenta os resultados das entrevistas realizadas com todos os gestores sobre os critérios competitivos. Os testes de hipóteses realizados demonstraram que não há diferenças significativas entre as respostas dos gestores, na medida em que o nível descritivo (p) é maior que 0,05 .

Tabela 1 - Critérios competitivos

\begin{tabular}{|c|c|c|c|c|c|c|c|c|c|}
\hline Empresas & \multicolumn{3}{|c|}{ ME } & \multirow{2}{*}{ 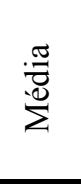 } & \multicolumn{3}{|c|}{$\mathrm{AL}$} & \multirow{2}{*}{ 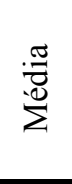 } & \multirow{2}{*}{$\begin{array}{c}\text { Teste } \\
\text { Mann-Whitney } \\
\begin{array}{c}\text { Nível descritivo } \\
\text { p }\end{array}\end{array}$} \\
\hline Critério & $\begin{array}{c}\text { Gestor } \\
\text { A }\end{array}$ & $\begin{array}{c}\text { Gestor } \\
\text { B }\end{array}$ & $\begin{array}{c}\text { Gestor } \\
\mathrm{C}\end{array}$ & & $\begin{array}{c}\text { Gestor } \\
\mathrm{A}\end{array}$ & $\begin{array}{c}\text { Gestor } \\
\text { B }\end{array}$ & $\begin{array}{c}\text { Gestor } \\
\mathrm{C}\end{array}$ & & \\
\hline Custo & 5 & 2 & 5 & 4 & 4 & 3 & 5 & 4 & 0,8273 \\
\hline Qualidade & 4 & 3 & 5 & 4 & 4 & 5 & 5 & 4,66 & 0,3827 \\
\hline Entrega & 4 & 5 & 5 & 4,66 & 5 & 3 & 5 & 4,33 & 0,8273 \\
\hline $\begin{array}{c}\text { Flexibilidade/ } \\
\text { tecnologias }\end{array}$ & 4 & 5 & 3 & 4 & 2 & 5 & 3 & 3,33 & 0,5127 \\
\hline Inovatividade & 5 & 5 & 5 & 5 & 1 & 5 & 5 & 3,66 & 0,5127 \\
\hline
\end{tabular}

Fonte: Pesquisa de campo (2009)

No que se refere aos critérios competitivos, os que mais se destacaram, na opinião dos gestores entrevistados, conforme figura 2, foram "inovatividade e entrega". Estes resultados não demonstram alinhamento com a resposta "custo", relatada pelos gestores na questão que abordava a principal estratégia adotada pela empresa. Nas entrevistas, foi destacado que o mercado de atuação da empresa ME baseia-se pelo preço. Porém, a empresa trabalha em inovação e qualidade, não sendo os atributos mais percebidos e/ou valorizados pelos clientes, por influência, talvez, da empresa ME não ser a líder de mercado. Já na empresa AL foram destacados "qualidade e entrega". Estes resultados demonstram o alinhamento com a resposta "diferenciação", relatada pelos gestores na questão que abordava as principais estratégias adotadas pela empresa. 
Figura 2 - Gráfico critérios competitivos.

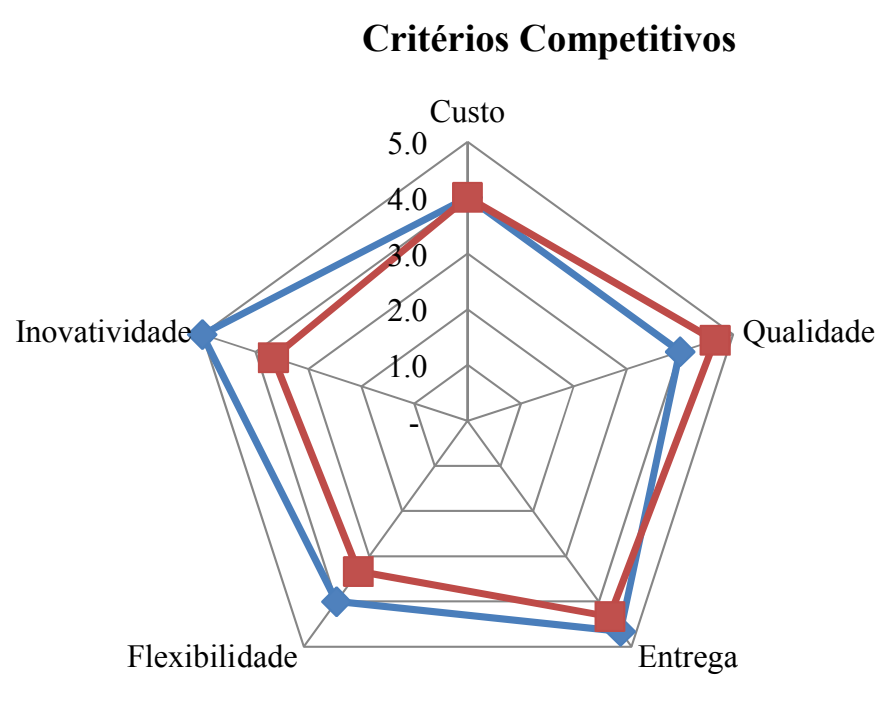

Fonte: Pesquisa de campo (2009)

Com relação às categorias de decisão, as empresas foram questionadas no sentido de que atribuíssem o grau de importância destas $(0=$ menos importante e $3=$ muito importante $)$.

A tabela 2 apresenta os resultados das entrevistas realizadas com todos os gestores sobre o grau de importância das categorias de decisão para as empresas. Os testes de hipóteses realizados demonstraram que não há diferenças significativas entre as respostas dos gestores, na medida que “p” é maior que 0,05 .

Tabela 2 - Grau de importância das categorias de decisão para as empresas

\begin{tabular}{|c|c|c|c|c|c|c|c|c|c|}
\hline Empresas & \multicolumn{3}{|c|}{ ME } & \multirow{2}{*}{ 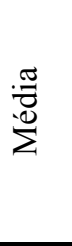 } & \multicolumn{3}{|c|}{$\mathrm{AL}$} & \multirow{2}{*}{ 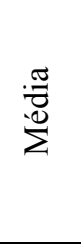 } & $\begin{array}{c}\text { Teste } \\
\text { Mann- }\end{array}$ \\
\hline $\begin{array}{c}\text { Categoria de } \\
\text { decisão }\end{array}$ & $\begin{array}{c}\text { Gestor } \\
\text { A }\end{array}$ & $\begin{array}{c}\text { Gestor } \\
\text { B }\end{array}$ & $\begin{array}{l}\text { Gestor } \\
\text { C }\end{array}$ & & $\begin{array}{c}\text { Gestor } \\
\text { A }\end{array}$ & $\begin{array}{l}\text { Gestor } \\
\text { B }\end{array}$ & $\begin{array}{l}\text { Gestor } \\
\text { C }\end{array}$ & & $\begin{array}{c}\text { Nível } \\
\text { descritivo } \\
\mathrm{p}\end{array}$ \\
\hline Capacidade & 2 & 3 & 3 & 2,66 & 3 & 3 & 2 & 2,66 & 1 \\
\hline Instalações & 3 & 2 & 3 & 2,66 & 3 & 3 & 3 & 3 & 0,1904 \\
\hline $\begin{array}{l}\text { Equipamentos e } \\
\text { Processos } \\
\text { tecnológicos }\end{array}$ & 3 & 3 & 3 & 3 & 3 & 3 & 3 & 3 & 1 \\
\hline $\begin{array}{l}\text { Integração vertical } \\
\text { e relação com os } \\
\text { fornecedores }\end{array}$ & 3 & 1 & 1 & 1,66 & 3 & 3 & 3 & 3 & 0,1904 \\
\hline Recursos Humanos & 3 & 3 & 3 & 3 & 1 & 3 & 2 & 2 & 0,1904 \\
\hline Qualidade & 3 & 3 & 3 & 3 & 2 & 3 & 3 & 2,66 & 0,5127 \\
\hline $\begin{array}{l}\text { Escopo e novos } \\
\text { produtos }\end{array}$ & 1 & 3 & 3 & 2,33 & 0 & 3 & 1 & 1,33 & $\mathbf{0 , 3 8 2 7}$ \\
\hline
\end{tabular}




\begin{tabular}{c|c|c|c|c|c|c|c|c|c}
\hline Sistemas Gerenciais & 2 & 3 & 3 & 2,66 & 1 & 3 & 3 & 2,33 & $\mathbf{0 , 8 2 7 3}$ \\
\hline $\begin{array}{c}\text { Relação Inter- } \\
\text { funcional }\end{array}$ & 3 & 3 & 3 & $\mathbf{3}$ & 1 & 3 & 3 & 2,33 & $\mathbf{0 , 5 1 2 7}$ \\
\hline
\end{tabular}

Fonte: Pesquisa de campo (2009)

Percebe-se na empresa ME, conforme figura 3, que as categorias de decisão consideradas mais importantes foram "equipamentos e processos tecnológicos", "recursos humanos", "qualidade" e "relação inter-funcional”. Já na empresa AL foram as "instalações", "equipamentos e processos tecnológicos", "integração vertical" e "relação com os fornecedores".

Dentro do processo de entrevista verificou-se que a estratégia competitiva da empresa $\mathrm{ME}$ caracteriza-se por custo, por atuar num mercado que existe mais oferta do que demanda. Com relação ao mercado de exportação, destaca-se a estratégia de "diferenciação", devido às exigências de mercado por qualidade. A empresa AL utiliza como estratégia a "diferenciação", uma vez que prioriza a qualidade e o aspecto visual do seu produto.

Figura 3 - Grau de Importância das Categorias de Decisão

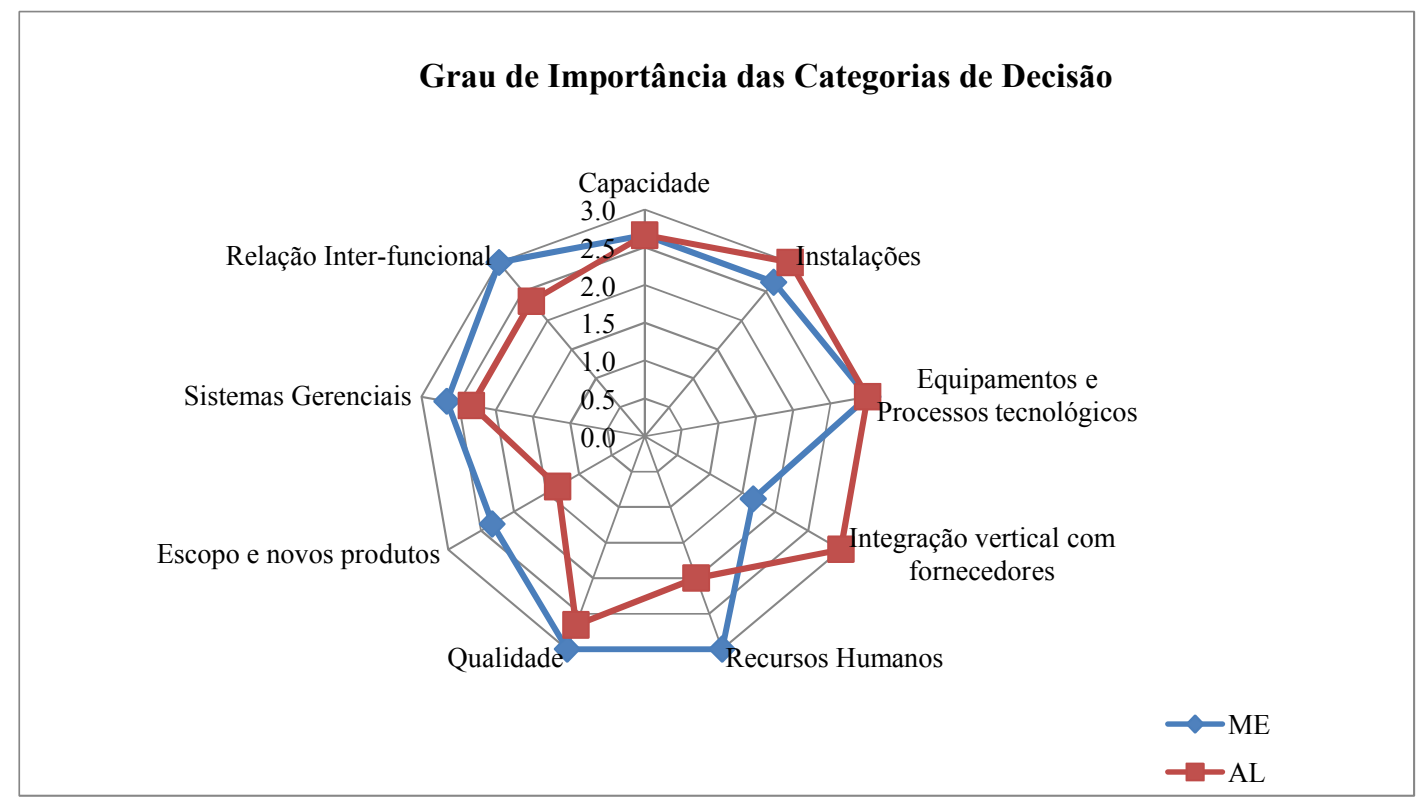

Fonte: Pesquisa de campo (2009)

A empresa AL não possui estratégias fixas, pois declara que existe uma dificuldade de traçarem-se estratégias de longo prazo. Isto se deve ao fato do segmento alimentício ser suscetível a variações de matérias-primas ou climáticas, além de barreiras sanitárias nacionais e internacionais.

A empresa ME possui suas estratégias claramente definidas no seu planejamento estratégico. Com a crise, a empresa optou estrategicamente em ampliar as suas linhas de produtos.

\subsection{Influências da crise nos resultados}


O quadro 3 apresenta os impactos percebidos e as estratégias, de acordo com oito aspectos abordados neste trabalho: mercado, melhoria do produto e inovação, pessoas, alianças, entrega, concorrentes, fornecedores e qualidade.

Segundo o entendimento da empresa ME, a crise influenciou diretamente o "mercado comprador interno" “... Como todos começaram a participar mais pelo mesmo pedaço do bolo também nos afetou no mercado nacional...", afirmou um dos executivos. Os principais problemas ocasionados foram a redução de faturamento e preços. Isso forçou a mesma a mudar parte de suas estratégias, buscando novas linhas de produtos, com uma reestruturação das áreas comercial e marketing, e acelerando o processo de parcerias e alianças com distribuidores, varejistas e clientes. Somado a isso, a empresa ME percebeu que poderia fazer o mercado obter uma maior percepção da qualidade do seu produto. Segundo Slack (1993, p. 185) este caso caracteriza uma zona de excesso da relação importância versus desempenho, ou seja, a empresa apresenta um desempenho superior, porém o cliente não os considera relevante na decisão de compra.

Quadro 3 - Impacto Percebido versus Estratégias Adotadas

\begin{tabular}{|c|c|c|c|c|}
\hline \multirow{2}{*}{ Aspectos } & \multicolumn{2}{|c|}{ Impacto percebido } & \multicolumn{2}{|l|}{ Estratégia } \\
\hline & ME & $\mathrm{AL}$ & ME & $\mathrm{AL}$ \\
\hline Mercado & $\begin{array}{l}\text { - Redução do } \\
\text { Faturamento } \\
\text { - Redução de Preços. }\end{array}$ & $\begin{array}{l}\text { - Redução do } \\
\text { Faturamento } \\
\text { - Redução de } \\
\text { Preços. }\end{array}$ & $\begin{array}{l}\text { - Oportunidade de } \\
\text { desenvolvimento no } \\
\text { mercado interno. } \\
\text { - Aumento do hall de } \\
\text { produtos. } \\
\text { - Reestruturação da área } \\
\text { comercial e marketing. } \\
\text { - Estruturação de área de } \\
\text { treinamento para clientes. } \\
\text { - Parcerias com } \\
\text { distribuidores e varejistas } \\
\text { - Alianças estratégicas com } \\
\text { clientes. }\end{array}$ & $\begin{array}{l}\text { - Atuação nos } \\
\text { mercados classe } \\
\text { A e B. }\end{array}$ \\
\hline $\begin{array}{l}\text { Produto e } \\
\text { Inovação }\end{array}$ & Não & Não & - & - \\
\hline Pessoas & Não & Não & $\begin{array}{l}\text { - Continuaram os } \\
\text { investimentos em } \\
\text { treinamentos. } \\
\text { - Reaproveitou-se mão de } \\
\text { obra interna para } \\
\text { reestruturação da área } \\
\text { comercial. }\end{array}$ & $\begin{array}{l}\text { - Redução de } \\
\text { custos e } \\
\text { investimentos } \\
\text { para manter o } \\
\text { quadro } \\
\text { funcional. }\end{array}$ \\
\hline Alianças & Não & Não & $\begin{array}{l}\text { Acelerou o processo de } \\
\text { alianças com clientes. }\end{array}$ & - \\
\hline Entrega & $\begin{array}{l}\text { Houve influência } \\
\text { positiva e melhorou-se a } \\
\text { entrega porque diminuiu } \\
\text { a demanda. }\end{array}$ & $\begin{array}{l}\text { Influência } \\
\text { negativa porque } \\
\text { houve um } \\
\text { excesso de } \\
\text { oferta de } \\
\text { produto no } \\
\text { mercado. } \\
\end{array}$ & - & $\begin{array}{l}\text { - A empresa } \\
\text { adotou como } \\
\text { estratégia focar } \\
\text { os pequenos } \\
\text { clientes que } \\
\text { possuem menos } \\
\text { estoque. }\end{array}$ \\
\hline Concorrentes & $\begin{array}{l}\text { - Aumento de atuação da } \\
\text { concorrência no } \\
\text { mercado. } \\
\text { - Redução de preços pela }\end{array}$ & $\begin{array}{l}\text { - Redução de } \\
\text { Preços. }\end{array}$ & $\begin{array}{l}\text { - Implantou-se um plano de } \\
\text { marketing para divulgação } \\
\text { da marca. Redução de custos } \\
\text { de processo. }\end{array}$ & $\begin{array}{l}\text { - Atuação nos } \\
\text { mercados classe } \\
\text { A e B. }\end{array}$ \\
\hline
\end{tabular}




\begin{tabular}{|c|c|c|c|c|}
\hline & concorrência. & & & \\
\hline Fornecedores & $\begin{array}{l}\text { - Necessidade de redução } \\
\text { dos custos. }\end{array}$ & $\begin{array}{l}\text { Não houve } \\
\text { problema } \\
\text { porque não se } \\
\text { alteraram as } \\
\text { condições de } \\
\text { pagamento, } \\
\text { entrega e preço. }\end{array}$ & $\begin{array}{l}\text { - Processo de seleção de } \\
\text { novos fornecedores. } \\
\text { - Campanha com os } \\
\text { fornecedores para redução } \\
\text { dos custos. }\end{array}$ & Não \\
\hline Qualidade & $\begin{array}{l}\text { - Maior oferta de } \\
\text { produtos com isso os } \\
\text { clientes tem maior opção } \\
\text { de escolha. Como } \\
\text { consequência mais } \\
\text { criteriosos. }\end{array}$ & Não & $\begin{array}{l}\text { - Controle maior dos } \\
\text { requisitos de qualidade. } \\
\text { - Foram feitos investimentos } \\
\text { em equipamentos de } \\
\text { controle, prevenção e } \\
\text { ferramental. }\end{array}$ & Não \\
\hline
\end{tabular}

Fonte: Pesquisa de campo (2009)

A empresa AL também foi afetada no que tange ao "mercado", porém por ser do ramo alimentício, que é uma necessidade básica, não sofreu impactos como empresas de outros segmentos. Contudo, reduziu investimentos de curto prazo, e passou a atuar fortemente em vendas dentro da região na qual estava sediada e do estado do RS. Um dos gestores acredita que a empresa foi hábil na questão de vendas, agilidade para a entrega, e na definição de mix de produtos específicos para certos clientes.

Quanto ao aspecto "inovação", a empresa ME vinha trabalhando em alguns projetos de novos produtos e, com o advento da crise, já tinha estes produtos desenvolvidos. Um dos executivos da empresa afirma “... talvez aí nós tivemos sorte porque a crise nos beneficiou. Não é só em função da crise, mas pelo trabalho que vinha sendo feito. A empresa veio desenvolvendo produtos de alto valor agregado e já tinha estes produtos...”. A empresa AL não identificou impactos sobre o "aspecto inovação".

No que se refere ao aspecto "pessoas" a crise não provocou demissões em ambas as empresas. Ao contrário, as mesmas optaram em reter os talentos, investir em treinamento e qualificação da mão de obra. Um dos gestores da empresa $\mathrm{AL}$ relatou “... as empresas perderam talentos por conta da crise, de uma forma geral. A AL não fez redução no quadro funcional, ao contrário, contratou para não perder em qualidade de produtos, na medida em que começou a atender varejistas mais exigentes neste período...”.

A AL não fez "alianças" durante o período de instabilidade, buscando somente o fortalecimento das relações com os clientes. Na ME foram realizadas parcerias com clientes e aliança formal com um grupo do segmento. Porém, tal aliança já havia sido planejada anteriormente e a crise apenas proporcionou acelerar este processo.

Quanto ao aspecto "entrega", para a empresa ME houve influência positiva, porque ao reduzir a demanda conseguiu-se equilibrar os estoques e implantar uma filosofia de "produção 
puxada". Na AL ocorreu influência negativa na "entrega" para os grandes compradores, uma vez que houve um excesso de oferta de produto no mercado interno. Este excesso foi causado pelo fato dos grandes produtores interromperem suas exportações, abastecendo o mercado com grandes volumes. Assim, a empresa adotou maior ênfase na estratégia de focar nos clientes menores, aplicando JUST IN TIME para o cliente, com pedidos menores, mais frequentes e sem estoque.

Referente ao aspecto "concorrentes", a empresa ME destacou que foi afetada pela baixa de preço de forma significativa, por parte do principal concorrente e líder de mercado. Este, por sua vez, possui marca conhecida e posicionada, além de ter um forte canal de distribuição. Segundo um dos executivos da empresa ME: “... No mercado nacional, infelizmente até o momento, não valorizam o diferencial e procuram preço...”. Os concorrentes da empresa AL reduziram o preço porque houve um excesso de oferta no mercado. Assim, a empresa adotou uma estratégia focada em outros públicos que não eram seu foco até o momento, classes A e B, que costumam comprar seus produtos em mercados especializados.

Em se tratando de "fornecedores", a empresa AL não obteve grandes mudanças, pois seu principal fornecedor de matéria-prima não foi afetado pela crise: além de abastecer os demais produtores do segmento com grandes quantidades de matéria-prima, o mesmo tinha alternativas de vendas, como excedente, do seu produto. Já na ME, os fornecedores das principais matérias-primas sentiram a crise e, desta forma, a empresa adotou como estratégia uma campanha para redução de custos, buscando, também, fornecedores alternativos.

No aspecto "qualidade" não houve influência na empresa AL. Na empresa ME, com a maior oferta de produtos pelo mercado, os clientes tiveram mais opções de escolha, resultando num aumento de exigência no padrão de qualidade do produto. Neste período, a empresa teve que investir em melhoria de equipamentos de controle, prevenção ferramental e maior controle nos requisitos dos clientes.

O quadro 6 apresenta as ações feitas pelas empresas para minimizar os impactos da crise sob a ótica dos critérios competitivos: custo, qualidade, inovação, entrega e flexibilidade. Também são apresentados alguns dos resultados obtidos pelas empresas com a implantação das ações durante a crise, os novos métodos de avaliação adotados e as mudanças ocorridas na condução das estratégias.

Referente ao critério competitivo "custo" a empresa ME iniciou mais de 30 projetos, visando negociação de custos financeiros com bancos, desenvolvimento de matérias-primas alternativas, redução de custos de transporte, racionalização dos processos de fabricação, redução do custo da não-qualidade, minimização dos gastos com telefone, planos de saúde e serviços ao cliente, dentre outros. Segundo um dos gestores da empresa ME: “...Com a crise os clientes começaram a reclamar mais por causa de custo, então a empresa focou em reduzir os custos internos com projetos de redução custos. Também foram feitos trabalhos dentro dos clientes 
para avaliação e melhorias dos processos dos mesmos ....". Na empresa AL o critério "custo" foi trabalhado sob uma perspectiva de melhorar o preço médio dos produtos e, através de uma revisão nos planos de investimento, buscou-se uma redução deste, mantendo investimentos prioritários em estrutura física. Os demais investimentos foram postergados.

Quanto ao critério competitivo "entrega", a empresa AL melhorou a taxa de ocupação dos caminhões através da revisão das rotas de transporte, o que propiciou que o mesmo veículo atendesse uma quantidade maior de clientes. Um dos gestores da empresa afirmou “... a taxa de ocupação dos caminhões saltou de $58 \%$ para mais de $\mathbf{7 0 \%}$. Como o mercado interno absorveu muito a produção neste período, a entrega foi favorecida...”.

Segundo os gestores das empresas, a crise proporcionou avaliar a forma de condução das estratégias existentes sob uma perspectiva de maior efetividade e ações consistentes.

O quadro 4 apresenta as ações feitas pelas empresas para minimizar os impactos da crise sob a ótica dos critérios competitivos: custo, qualidade, inovação, entrega e flexibilidade. Também são apresentados alguns dos resultados obtidos pelas empresas com a implantação das ações durante a crise, os novos métodos de avaliação adotados e as mudanças ocorridas na condução das estratégias.

Quadro 4 - Ações feitas pelas empresas para minimizar o impacto da crise

\begin{tabular}{|c|c|c|c|c|}
\hline \multirow{2}{*}{ Aspectos } & \multicolumn{2}{|c|}{ Impacto percebido } & \multicolumn{2}{|c|}{ Estratégia } \\
\hline & $\mathrm{ME}$ & $\mathrm{AL}$ & $\mathrm{ME}$ & $\mathrm{AL}$ \\
\hline Mercado & $\begin{array}{l}\text { - Redução do } \\
\text { Faturamento } \\
\text { - Redução de } \\
\text { Preços. }\end{array}$ & $\begin{array}{l}\text { - Redução do } \\
\text { Faturamento } \\
\text { - Redução de } \\
\text { Preços. }\end{array}$ & $\begin{array}{l}\text { - Oportunidade de } \\
\text { desenvolvimento no } \\
\text { mercado interno. } \\
\text { - Aumento do hall de } \\
\text { produtos. } \\
\text { - Reestruturação da área } \\
\text { comercial e marketing. } \\
\text { - Estruturação de área de } \\
\text { treinamento para clientes. } \\
\text { - Parcerias com } \\
\text { distribuidores e varejistas } \\
\text { - Alianças estratégicas } \\
\text { com clientes. }\end{array}$ & $\begin{array}{l}\text { - Atuação nos } \\
\text { mercados classe A e } \\
\text { B. }\end{array}$ \\
\hline $\begin{array}{l}\text { Melhoria do } \\
\text { Produto e } \\
\text { Inovação }\end{array}$ & Não & Não & - & - \\
\hline Pessoas & Não & Não & $\begin{array}{l}\text { - Continuaram os } \\
\text { investimentos em } \\
\text { treinamentos. } \\
\text { - Reaproveitou-se mão de } \\
\text { obra interna para } \\
\text { reestruturação da área } \\
\text { comercial. }\end{array}$ & $\begin{array}{l}\text { - Redução de custos } \\
\text { e investimentos para } \\
\text { manter o quadro } \\
\text { funcional. }\end{array}$ \\
\hline Alianças & Não & Não & $\begin{array}{l}\text { Acelerou o processo de } \\
\text { alianças com clientes. }\end{array}$ & - \\
\hline Entrega & $\begin{array}{l}\text { Houve influência } \\
\text { positiva e } \\
\text { melhorou-se a } \\
\text { entrega porque } \\
\text { diminuiu a } \\
\text { demanda. }\end{array}$ & $\begin{array}{l}\text { Influência negativa } \\
\text { porque houve um } \\
\text { excesso de oferta de } \\
\text { produto no } \\
\text { mercado. Influência } \\
\text { para os grandes }\end{array}$ & - & $\begin{array}{l}\text { - A empresa adotou } \\
\text { como estratégia } \\
\text { focar os pequenos } \\
\text { clientes que } \\
\text { possuem menos } \\
\text { estoque. }\end{array}$ \\
\hline
\end{tabular}




\begin{tabular}{|c|l|l|l|l|}
\hline & & compradores & & \\
\hline Concorrentes & $\begin{array}{l}\text { - Aumento de } \\
\text { atuação da } \\
\text { concorrência no } \\
\text { mercado. } \\
\text { - Redução de } \\
\text { preços pela } \\
\text { concorrência. }\end{array}$ & $\begin{array}{l}\text { - Redução de } \\
\text { Preços. }\end{array}$ & $\begin{array}{l}\text { - Implantou-se um plano } \\
\text { de marketing para } \\
\text { divulgação da marca. } \\
\text { - Redução de custos de } \\
\text { processo. }\end{array}$ & $\begin{array}{l}\text { B. Atuação nos } \\
\text { mercados classe A e }\end{array}$ \\
\hline Fornecedores & $\begin{array}{l}\text { - Necessidade de } \\
\text { redução dos custos. }\end{array}$ & $\begin{array}{l}\text { não se alteraram as } \\
\text { condiçães de } \\
\text { pagamento, entrega } \\
\text { e preço. }\end{array}$ & $\begin{array}{l}\text { novos fornecedores. } \\
\text { - Campanha com os } \\
\text { fornecedores para redução } \\
\text { dos custos. }\end{array}$ & Não \\
\hline Qualidade & $\begin{array}{l}\text { - Maior oferta de } \\
\text { produtos com isso } \\
\text { os clientes tem } \\
\text { maior opção de } \\
\text { escolha. Como } \\
\text { consequência mais } \\
\text { criteriosos. }\end{array}$ & $\begin{array}{l}\text { - Controle maior dos } \\
\text { requisitos de qualidade. } \\
\text { - Foram feitos } \\
\text { investimentos em } \\
\text { equipamentos de controle, } \\
\text { prevenção e ferramental. }\end{array}$ & Não \\
\hline
\end{tabular}

Fonte: Pesquisa de campo (2009)

$\mathrm{O}$ quadro 5 apresenta as questões relacionadas às estratégias adotadas durante o período de crise e a visão dos gestores sobre a área de recursos humanos. Os gestores entrevistados destacaram que não foram realizadas demissões e, ao contrário, as empresas investiram em treinamento dos funcionários.

Para Fleury (2003), uma empresa, para ser competitiva, precisa compreender como se articulam competência essencial e estratégia empresarial ao processo de criação de vantagens competitivas. Dentro da visão deste autor a área de recursos humanos tem papel significativo na gestão estratégica da empresa.

Quadro 5 - Questões da crise relacionadas a recursos humanos

\begin{tabular}{|c|c|c|}
\hline Questão & \multicolumn{1}{|c|}{ ME } & AL \\
\hline $\begin{array}{c}\text { Se a empresa considera importante } \\
\text { a área de gestão de pessoas }\end{array}$ & $\begin{array}{c}100 \% \text { dos entrevistados disseram } \\
\text { que sim. }\end{array}$ & $\begin{array}{c}100 \% \text { dos entrevistados disseram que } \\
\text { sim. }\end{array}$ \\
\hline $\begin{array}{c}\text { Qual é o \% de faturamento que } \\
\text { investe em recursos humanos? }\end{array}$ & $3 \%$ & Não disponibilizou o dado \\
\hline $\begin{array}{c}\text { A crise afetou as estratégias de } \\
\text { recursos humanos. }\end{array}$ & NÃO & NÃO \\
\hline Estratégias do RH devido à crise. & $\begin{array}{l}\text { - Não repor o quadro funcional. } \\
\text { - Treinamento dos funcionários. } \\
\text { horas. }\end{array}$ & $\begin{array}{l}\text { - Reduçãão de investimentos em outras } \\
\text { áreas para manutenção do quadro } \\
\text { funcional. } \\
\text { dreinamento dos funcionários. }\end{array}$ \\
\hline
\end{tabular}

Fonte: Pesquisa de campo (2009)

\subsection{Visão das empresas e oportunidades sobre a ótica alianças}


No quadro 6 são destacados, sob a ótica dos gestores, quais seriam os principais motivos que levariam as empresas a participarem de alianças. Na empresa ME os gestores destacaram que a crise favoreceu a aceleração de um processo de aliança que estava em andamento. Um dos executivos declarou que “... se não houvesse a crise, talvez não tivéssemos feito o contrato. Só tivemos esta oportunidade porque havia sido feito um trabalho anterior...".

A presença de empresas estrangeiras pode ajudar as empresas locais a melhorar suas técnicas de gestão, produção e comercialização, através da aquisição de inputs sofisticados, da pressão concorrencial e da circulação de pessoal diretivo e executivo formado em sociedades multinacionais (BONAGLIA; GOLDSTEIN, p. 71, 2006).

Quadro 6 - Visão e oportunidades relativas às alianças

\begin{tabular}{|c|c|c|}
\hline Questão & ME & $\mathrm{AL}$ \\
\hline $\begin{array}{l}\text { Ocorrência de alianças, } \\
\text { parcerias, fusões entre } \\
\text { outros no segmento de } \\
\text { atuação. }\end{array}$ & $\begin{array}{l}\text { Recentemente várias empresas do } \\
\text { segmento ao redor do mundo uniram-se, } \\
\text { fecharam ou fizeram fusões com outras } \\
\text { empresas. }\end{array}$ & $\begin{array}{l}\text { - Em empresas de maior porte, é comum a } \\
\text { aquisição entre empresas. } \\
\text { - Parcerias são restritas à fabricação de } \\
\text { alguns itens em que uma planta possui } \\
\text { tecnologia e outra não, ou por oferecimento } \\
\text { de capacidade ociosa para determinada } \\
\text { atividade. } \\
\text { - É importante o bom relacionamento com } \\
\text { os demais do mesmo ramo. }\end{array}$ \\
\hline $\begin{array}{l}\text { Fatores determinantes } \\
\text { para a realização de } \\
\text { alianças, parcerias, } \\
\text { fusões entre outros. }\end{array}$ & $\begin{array}{l}\text { - Fortalecimento da marca. } \\
\text { - Maiores recursos para investimentos em } \\
\text { melhorias. } \\
\text { - Troca de tecnologias e experiências. } \\
\text { - Aumento do hall de produtos. }\end{array}$ & $\begin{array}{l}\text { - Rentabilidade. } \\
\text { - Colocação em outros mercados. } \\
\text { - Domínio maior do mercado. } \\
\text { - Redução de custos. } \\
\text { - Aumento do volume de produção. }\end{array}$ \\
\hline $\begin{array}{l}\text { Ocorrência de } \\
\text { interferência nos } \\
\text { resultados da empresa } \\
\text { devido à realização de } \\
\text { alianças, parcerias, } \\
\text { fusões entre outros na } \\
\text { concorrência ou com a } \\
\text { própria organização. }\end{array}$ & $\begin{array}{l}\text { A empresa foi afetada positivamente pela } \\
\text { aliança que foi feita com um cliente } \\
\text { americano e pela fusão realizada com } \\
\text { empresa do segmento. }\end{array}$ & $\begin{array}{l}\text { Houve fusões entre empresas do segmento } \\
\text { de atuação muito recentemente e ainda não } \\
\text { influenciaram na organização. }\end{array}$ \\
\hline
\end{tabular}

Fonte: Pesquisa de campo (2009)

\section{Conclusão}

O objetivo desta pesquisa foi diagnosticar quais foram as ações adotadas por duas empresas no período de crise, sob a ótica dos critérios competitivos, repensando suas estratégias de operação.

A ME é uma empresa brasileira, com mais de 20 anos, de médio porte, que atua no segmento de autopeças em todo o mercado nacional e exporta para os cinco continentes. É uma empresa que, na visão de seus gestores, compete por custos e trabalha com ênfase em inovação e entrega. A AL é uma empresa brasileira, com mais de 30 anos, de grande porte, que atua no segmento alimentício com ênfase no mercado gaúcho, exportando para os mercados russo, oriente médio e asiático. É uma empresa que, na visão de seus gestores, compete por diferenciação e trabalha com ênfase em qualidade e entrega. No caso desta empresa, por uma decisão de estratégia 
de novas instalações físicas, a mesma interrompeu as atividades de exportação em 2009, minimizando os impactos da crise sobre este mercado.

Percebeu-se, na empresa ME, que as categorias de decisão consideradas mais importantes pelos executivos foram "equipamentos e processos tecnológicos", "recursos humanos", "qualidade" e "relação interfuncional". Já na AL foram as "instalações", “equipamentos e processos tecnológicos", "integração vertical" e "relação com os fornecedores".

$\mathrm{Na}$ empresa ME destacou-se que, no período da crise, aceleraram-se processos de alianças, ações voltadas a treinamento de funcionários, negociação com fornecedores, ampliação do mix de produtos, investimentos em infra-estrutura e tecnologias, implantação de projetos para redução de custos e melhoria da qualidade. O período de crise econômica também possibilitou identificar a real percepção do cliente em relação aos aspectos custo e qualidade. Na empresa AL, evidenciou-se que as estratégias relacionadas à qualidade do produto, entrega e recursos humanos tiveram oportunidades de melhoria durante o período de crise, ao mesmo tempo em que os investimentos foram reavaliados quanto às prioridades de execução.

Constatou-se que as empresas pesquisadas conseguiram manter-se estáveis durante o período de crise, principalmente pelo fato de possuírem estratégias definidas e dedicarem-se na melhoria dos seus processos internos. Conforme os entrevistados, a crise oportunizou uma visão mais crítica sobre as estratégias existentes nas empresas.

Apesar de, durante as entrevistas, as respostas dos gestores das empresas não serem alinhadas, o teste Mann-Whitney mostrou que a divergência entre estas respostas não foi significativa. A partir disto, pode-se concluir que ambas as empresas compartilharam de estratégias similares para manterem-se estáveis dentro do período da crise, embora de segmentos diferentes.

\begin{abstract}
On the second semester of 2008 the economic crisis started causing an influence on the organizational results of several companies. The managers had to be agile in analysis to find out on which competitive criteria the companies were threaten as they could decide the strategies to use in order to keep themselves in the globalized market. The purpose of this research was to identify diagnosis on which were the actions adopted by two companies in the crisis period, based on the competitive criteria rethinking their performing strategy. The methodology applied was classified as an exploratory research (case study) with the use of interviews with half-structured questions. For this research there were used the five competitive criteria mentioned by Paiva et al. (2004). As objects of this research two export companies were selected: one of them from the food segment and another from automobile parts segment. The results showed that besides the differences in the segments of these companies, both of them presented actions with a common level of significancy and as they already had definite strategies before the crisis period they were affected superficially.
\end{abstract}

Key-words: global crisis; competitive criteria; decision categories; performing strategies.

\title{
Referências
}

BONAGLIA, F.; GOLDSTEIN, A. Globalização e Desenvolvimento. Lisboa, PO: Presença, 2006, 134p. 
CARVALHO, M. F. H. Metodologia para constituição de parceria entre empresas. Revista Produção on Line. v.7, n.1, p.187-206, abr., 2007.

CHASE, R. B.; et al. Administração da produção para vantagem competitiva. 10 ed. Porto Alegre, RS: Bookman, 2006. 724 p.

CHING, H. Y. Gestão de estoques na cadeia de logística integrada: supply chain. São Paulo: Atlas, 1999. 182p.

COOPER, M. C.; LAMBERT, D. M. Issues in Supply Chain Management. Industrial Marketing Management, n.29, p. $65-83,2000$.

FLEURY, A. C. C.; FLEURY, M. T. L. Estratégias competitivas e competências essenciais: perspectivas para a internacionalização da indústria no Brasil. Gestão \& Produção, v.10, n.2, p. 129-144, ago. 2003.

HAYES, D. K.; NINEMEIER, J. D. Gestão de organizações hoteleiras. São Paulo: Pearson Prentice Hall, 2005. $386 \mathrm{p}$.

GIL, A. C. Como elaborar projetos de pesquisa. 4.ed. São Paulo: Atlas, 2002175 p.

KPMG. Financial Advisory Services. Pesquisa de fusões e aquisições: espelho das transações realizadas no Brasil. Brasil, 2009. Disponível em: <http://www.kpmg.com.br/publicacoes_fas.asp?ft=5\&fx=16>. Acesso em: 03 Jul. 2009.

MÁlAGA, F. K. Estudo do Risco Sistêmico das Empresas Resultantes de Fusões e Aquisições e as Expectativas dos Investidores e dos Gestores. São Paulo, 2007. 2003 p. Tese - Universidade de São Paulo - Faculdade de Economia, Administração e Contabilidade.

MARTINS, G. A. Estatística geral e aplicada. 2.ed. São Paulo: Atlas, 2002. 417 p.

OLIVEIRA, O. V. Fusões e aquisições sob a perspectiva da vantagem competitiva: o caso da Perdigão Agroindustrial S.A. RBGN, São Paulo. v.8, n.22, p.46-56, set/dez., 2006.

PAIVA, E. L.; FENITERSEIFER, J. E.; CARVALHO JR., J. M. Estratégia de produção e de operações: conceitos, melhores práticas, visão do futuro. Porto Alegre: Bookman, 2004. 192 p. (Administração / operações).

PORTER, M. E. Vantagem competitiva: criando e sustentando um desempenho superior. 23.ed. Rio de Janeiro: Campus, 2003. 512 p.

PORTER, M. E.; MONTGOMERY, C. A. Estratégia: a busca da vantagem competitiva. 6.ed. Rio de Janeiro: Campus, 2001. $501 \mathrm{p}$.

SLACK, N. Vantagem competitiva em manufatura: atingindo competitividade nas operações industriais. São Paulo: Atlas, 1993. 198 p.

VASCONCELOS; L. C. S.; NASCIMENTO; A. Q.; MOREIRA; M. C.; MENDES; E. S. Politicas públicas para a agricultura familiar: um estudo de caso do PRONAF no assentamento corixinha, Cáceres/MT. In: XIV Encontro Nacional de Geografia, 2006, Acre. Anais... XIV Encontro Nacional De Geógrafos, 2006, v. único.

YIN, R. K. Estudo de caso: planejamento e métodos. 2.ed. Porto Alegre: Bookman, 2008. 205 p.

\section{Nome completo: Charles Rui}

Filiação institucional: UCS - Universidade de Caxias do Sul

Departamento: Programa de Mestrado em Administração

Função ou cargo ocupado: Dissente do curso de mestrado

Endereço completo para correspondência (bairro, cidade, estado, país e CEP): Rua Flamingo, 626,

Bairro Flamingo, Caxias do Sul, RS, Brasil, 95095-140

Telefones para contato: (54) 3226-3877 (54) 99283554 
Nome completo: Ricardo Antonio Reche

Filiação institucional: Universidade de Caxias do Sul

Departamento: Programa de Mestrado em Administração

Função ou cargo ocupado: Dissente do curso de mestrado

Endereço completo para correspondência (bairro, cidade, estado, país e CEP): Rua Buarque de Macedo, 3292, bloco 2, apto 401, bairro Centro, Garibaldi-RS, CEP 95720-000

Telefones para contato: (54) 3462-4172 ou (51) 9932-9476

e-mail: ricardo.reche@yahoo.com.brouricardo.reche@hotmail.com

Nome completo: Beatriz Lucia Salvador Bizotto

Filiação institucional: UCS- Universidade de Caxias do Sul

Departamento: Programa de Mestrado em Administração

Função ou cargo: Dissente do curso de mestrado

Endereço completo para correspondência: Rua Ramiro Barcelos, 1810 centro CEP 95200-000

Vacaria/RS - Brasil

Telefones para contato (54) 3231-6013 ou (54) 32313099 ou (54) 99837159

e-mail:beatriz.bizotto@uol.com.br;bmcontabilidade@bmcontabilidade.com.br

Nome completo: Evandro Lazzarotto

Filiação institucional: Universidade de Caxias do Sul

Departamento: Programa de Mestrado em Administração

Função ou cargo ocupado: Dissente do curso de mestrado

Endereço completo para correspondência (bairro, cidade, estado, país e CEP): Rua Ruy Cavagnolli, $\mathrm{n}^{\circ}$ 8, Bairro Santa Corona, CEP 95088-280 - Caxias do Sul - RS

Telefones para contato: (54) 32895510 ou (54) 32267757 ou (54) 91698895 ou (54) 32895501

e-mail:lazzarotto.e@ognibene.com

Nome completo: Carlos Alberto Costa

Filiação institucional: Universidade de Caxias do Sul

Departamento: Engenharia Mecânica

Função ou cargo ocupado: PROFESSOR / PESQUISADOR

Endereço completo para correspondência: (bairro, cidade, estado, país e CEP): Rua

Domingos Vanoni, 56 - apto 401, Bairro Madureira, Caxias do Sul - 95040-190

Telefones para contato: (54) 3218-2160

e-mail:cacosta@ucs.br 
Nome completo: Maria Emilia Camargo

Filiação institucional: Universidade de Caxias do Sul

Departamento: Programa de Mestrado em Administração

Função ou cargo ocupado: Professora

Endereço completo para correspondência (bairro, cidade, estado, país e CEP): Av. João Machado Soares, 3199, CEP 97.10-000 - Santa Maria, RS

Telefones para contato: (55) 32261348 ou (55) 99728225

e-mail:kamargo@terra.com.br

Enviado em: 25/09/2009

Aprovado em:02/03/2011 